\title{
Processing of Urushiol (Poison Ivy) Hapten by Both Endogenous and Exogenous Pathways for Presentation to T Cells In Vitro
}

\author{
Richard S. Kalish, Jonathan A. Wood, and Axel LaPorte \\ Department of Dermatology, State University of New York at Stony Brook, Stony Brook, New York 11794-8165
}

\begin{abstract}
The antigen processing requirements for urushiol, the immunogen of poison ivy (Toxicodendron radicans), were tested by presentation of urushiol to cultured human urushiol-responsive T cells. Urushiol was added to antigen-presenting cells (APC) either before or after fixation with paraformaldehyde. Three distinct routes of antigen processing were detected. CD8+ and CD4+ T cells, which were dependent upon processing, proliferated if urushiol was added to APC before fixation, but did not proliferate when urushiol was added to APC after fixation. Processing of urushiol for presentation to CD8 + T cells was inhibited by azide, monensin, and brefeldin $A$. This suggests that urushiol was processed by the endogenous pathway. In contrast, presentation of urushiol to CD4 $+\mathrm{T}$ cells was inhibited by monensin but not by brefeldin $A$. This was compatible with antigen processing by the endosomal (exogenous) pathway. Finally, certain CD8 $+\mathrm{T}$ cells recognized urushiol in the absence of processing. These cells proliferated in response to APC incubated with urushiol after fixation. Classification of contact allergens by antigen processing pathway may predict the relative roles of CD4+ and CD8 + cells in the immunopathogenesis of allergic contact dermatitis. (J. Clin. Invest. 1994. 93:20392047.) Key words: antigen-presenting cells • T lymphocytes • haptens • dermatitis • allergic contact
\end{abstract}

\section{Introduction}

Antigen processing can proceed by distinct pathways. These pathways may determine the relative contributions of CD4+ and CD8 + $\mathrm{T}$ cells in an immune response as well as the immunopathology induced by an antigen. Haptens conjugate proteins by a variety of chemical reactions and have a broad range of physical properties. It is likely that this diversity in the chemical properties of haptens is reflected in a diversity of antigen processing and presentation pathways.

Urushiol is the active immunogen of poison ivy and poison oak $(1,2)$. It is a lipid-soluble molecule composed of a catechol nucleus substituted on $\mathrm{C} 4$ with a $\mathrm{C} 15$ (poison ivy) or $\mathrm{C} 17$ (poison oak) hydrophobic tail $(3,4)$. Covalent binding of urushiol to proteins requires oxidation to a quinone intermediate (5) which is susceptible to nucleophilic substitution by amino

Address correspondence to Richard S. Kalish, Department of Dermatology, Health Science Center T-16 Room 60, State University of New York at Stony Brook, Stony Brook, NY 11794-8165.

Received for publication 30 July 1993 and in revised form 12 January 1994.

J. Clin. Invest.

(c) The American Society for Clinical Investigation, Inc. 0021-9738/94/05/2039/09 \$2.00

Volume 93, May 1994, 2039-2047 groups or sulfhydryl groups. An alternative mechanism of activation involving oxidation to free radical intermediates has also been proposed (6).

Antigen processing proceeds by different pathways depending upon whether the antigen is an extrinsic protein or an endogenously synthesized protein (7-9). Extrinsic antigens are phagocytosed or endocytosed and degraded into peptides within the endosome/lysosome compartment. Processed antigenic peptides associate with class II MHC molecules within the endosome/lysosome compartment for eventual presentation to CD4+ T cells. Newly synthesized MHC class II molecules are prevented from binding peptides before transport to the endosomal compartment by association with the invariant chain (10). Inhibitors that interfere with endosome-dependent protein processing include chloroquine (11), monensin (12), leupeptin (13), and ammonium chloride (11). Peptides isolated from murine MHC class II molecules include secretory and membrane proteins with access to endosomal compartments (14).

In contrast, proteins synthesized endogenously are degraded into peptides and transported into the endoplasmic reticulum where they associate with class I MHC molecules for eventual presentation to CD8+ T cells. Degradation of cytoplasmic proteins into peptides of approximately nine amino acids in length is believed to be a function of the proteasome complex (15), a 26S multisubunit complex with protease activity. The genes for several subunits of this complex are linked to the MHC class II region $(16,17)$. Transport of cytoplasmic peptides into the endoplasmic reticulum is dependent upon transporter proteins which bind ATP and are coded by the Tap- 1 and Tap- 2 genes, which also map within the MHC class II region (18-21 ). T2 cells are defective in this ability to transport peptides and are unable to process endogenous peptides for presentation on MHC class I $(22,23)$. Class I MHC molecules associate with peptides within the endoplasmic reticulum and are transported to the golgi complex for presentation on the cell surface (24). In addition to its effects on endosomal antigen processing, monensin disrupts the golgi complex, inhibiting transport to the plasma membrane (25). Brefeldin A interferes with transport of proteins from the endoplasmic reticulum to the golgi complex (26), thereby inhibiting presentation of proteins dependent upon the endogenous presentation pathway (27).

Since MHC class II molecules present to CD4+ cells and class I MHC molecules present to CD8+ cells, extrinsic antigens are recognized by CD4+ cells, and endogenous peptides are recognized by CD8+ cells. This correlation is not absolute, as under certain circumstances endogenous antigens may be presented by MHC class II molecules (28).

A high proportion of CD8+ human urushiol-specific $\mathrm{T}$ cell clones are CD8+ (29-31), and class I MHC restriction was demonstrated for one such urushiol-specific clone (29). This suggests that processing of urushiol-conjugated proteins proceeds by the endogenous pathway. There is also murine evi- 
dence for $\mathrm{CD} 8+\mathrm{T}$ cell recognition of such haptens as dinitrofluorobenzene $(D N F B)^{1}(32)$. Since urushiol is an exogenous substance, we hypothesized that the lipid-soluble molecule enters the cell, conjugates intracellular proteins, and is presented by MHC class I molecules to CD8+ cells.

The goal of this study was to determine the antigen processing requirements for urushiol. Processing requirements were studied by the addition of urushiol to antigen-presenting cells (APC) either before or after fixation with paraformaldehyde. Antigen processing pathways were further delineated by the use of inhibitors.

\section{Methods}

Urushiol. Purified urushiol was the generous gift of Dr. H. Baer of the Bureau of Biologics, Food and Drug Administration (Bethesda, MD). Analysis of the purified urushiol by gas chromatography showed no saturated side chains and a minimum of $95 \%$ catechol (Dr. Alfred V. Del Grosso, personal communication). The material was $85.1 \% \mathrm{C} 15$ triene, $10.2 \%$ combination mono and diene, and $4.7 \% \mathrm{C} 17$ triene. Urushiol was used in cell culture at a concentration of $1.0 \mu \mathrm{g} / \mathrm{ml} \mathrm{(31).}$

Tetanus toxoid. Tetanus toxoid was obtained from the Massachusetts State Biological Laboratory (Jamaica Plain, MA) and was used at a 1:200 final dilution.

Generation of short-term human $T$ cell lines responsive to urushiol or tetanus toxoid. PBMC isolated from heparinized blood by centrifugation over Ficoll-Hypaque (Pharmacia LKB Biotechnology Inc., Piscataway, $\mathrm{NJ})$ were suspended with urushiol $(1 \mu \mathrm{g} / \mathrm{ml})$ or tetanus toxoid (1:200) at $1 \times 10^{6}$ cells $/ \mathrm{ml}$ in AIM V medium (GIBCO BRL, Gaithersburg, MD) and plated $1.0 \mathrm{ml} /$ well in 24-well plates. Starting on day 5 , media were changed every 3-4 d with AIM V media containing recombinant IL-2 ( $5 \mathrm{U} / \mathrm{ml}$; Boehringer Mannheim Corp., Indianapolis, IN). All $\mathrm{T}$ cell lines were derived independently over $2 \mathrm{yr}$ from the same donor selected for strong in vitro response to urushiol. An autologous EBV transformed B cell line (EBV817) was prepared from the same donor. Informed consent was obtained, and protocols were approved by the institutional review board of State University of New York at Stony Brook.

Isolation of CD4+ and CD8+ T cells by negative selection with magnetic particles. After 2 wk of culture, cultured $T$ cells were purified by sheep erythrocyte rosetting as described previously (33). CD4+ and CD8 + $T$ cells were then purified by negative selection with magnetic particles. T cells $\left(10 \times 10^{6}\right.$ cells $/ 15-\mathrm{ml}$ tube $)$ were incubated with 0.75 $\mathrm{ml}$ of a 1:250 dilution of appropriate ascites (anti-CD4, 19Thy5D7; anti-CD8, 7Pt3F9) on ice for $30 \mathrm{~min}$ and washed three times. Magnetic particles conjugated with goat anti-mouse IgG (Advanced Magnetics, Inc., Cambridge, MA) were washed four times and resuspended in suspension culture MEM (S-MEM) $/ 2.5 \%$ newborn calf serum $(\mathrm{NBCS})$ at $5 \times 10^{8}$ particles $/ \mathrm{ml}$. The magnetic particles $(1.0 \mathrm{ml})$ were then added to the $T$ cell pellet, which was resuspended and incubated on ice for $30 \mathrm{~min}$. Magnetic particles and associated cells were brought up to a total volume of $7.0 \mathrm{ml}$, and magnetic particles were removed by two magnetic separations ( $7 \mathrm{~min}$ each ). Negatively selected cells were then washed twice and resuspended in AIM V media. Both CD4+ and $\mathrm{CD} 8+$ cells were frequently selected from the same $\mathrm{T}$ cell line and are designated with the same experiment number.

Pretreatment of $A P C$. APC were preincubated with urushiol $(1 \mu \mathrm{g} /$ $\mathrm{ml})$ or tetanus toxoid $(1: 200)$ as indicated for $1 \mathrm{~h}$ at $37^{\circ} \mathrm{C}$. Inhibitors were added $1 \mathrm{~h}$ before antigen and remained present during the antigen incubation. Inhibitors included monensin (Calbiochem-Novabiochem

1. Abbreviations used in this paper: APC, antigen-presenting cells; DNFB, dinitrofluorobenzene; dpm, disintegrations per minute; (E-), erythrocyte rosette negative fraction; NBCS, newborn calf serum; SMEM, suspension culture MEM; TNP, trinitrophenol.
Corp., La Jolla, CA), azide (Sigma Immunochemicals, St. Louis, MO), and brefeldin A (Sigma Immunochemicals).

Paraformaldehyde fixation of APC. After preincubations as above, APC were fixed in $0.12 \%$ paraformaldehyde by a modification of published procedures $(12,34)$. Freshly prepared paraformaldehyde was added to APC ( $1.0 \mathrm{ml}$ to a pellet of $1.5 \times 10^{6}$ cells in a $5-\mathrm{ml}$ tube $)$ for a 5 -min incubation at $25^{\circ} \mathrm{C}$. Incubation was stopped by the addition of $4.0 \mathrm{ml}$ of glycine buffer $(0.15 \mathrm{M}, \mathrm{pH} 7.4)$, followed by three washes with S-MEM containing $2.5 \%$ heat-inactivated NBCS.

$T$ cell proliferation assays. Cultured CD4+ and CD8+ T cells were washed twice and incubated at $37^{\circ} \mathrm{C}$ for $2 \mathrm{~h}$ in S-MEM/2.5\% NBCS before a final wash, after which they were resuspended at $2.5 \times 10^{5}$ cells $/ \mathrm{ml}$ in AIM V medium. T cells $(0.1 \mathrm{ml})$ were added to $\operatorname{APC}(0.1$ $\mathrm{ml}$ ) in 96-well U-bottom plates for a total volume of $0.2 \mathrm{ml} /$ well. Replicates of six wells were used for each treatment group. When indicated, anti-CD28 ascites (4B10, obtained from Chikao Morimoto, Dana-Farber Cancer Institute, Boston, MA) were added to the wells at a final dilution of 1:500 (35). Wells were pulsed with $\left[{ }^{3} \mathrm{H}\right]$ thymidine $(1 \mu \mathrm{Ci} /$ well; New England Nuclear/Dupont, Boston, MA) at $24 \mathrm{~h}$, harvested $18 \mathrm{~h}$ later, and counted with a liquid scintillation counter (Pharmacia LKB Nuclear, Gaithersburg, MD). Proliferation was calculated as mean disintegrations per minute $(\mathrm{dpm})$ and is shown along with SEM.

Cytofluorograph analysis of cell phenotype. $\mathrm{T}$ cell lines were phenotyped after indirect immunofluorescence staining with anti-CD3 (RW2-8C8; IgG ${ }_{1}$ ), anti-CD4 (19Thy5D7; IgG ), anti-CD8 (7PT3F9; $\mathrm{IgG}_{2}$ ) (above antibodies obtained from Dr. Chikao Morimoto), antiCD2 (T11; Coulter Corp., Hialeah, FL), anti-B1 (Coulter Corp.), antiMO1 (Coulter Corp.), and anti-T cell receptor- $\delta 1$ (T-Cell Diagnostics, Cambridge, MA) followed by goat anti-mouse FITC (Sigma Immunochemicals). Mouse IgG (Coulter Corp.) was used as a negative control. $T$ cells separated by magnetic bead separation were analyzed by direct immunofluorescence with FITC-conjugated mouse IgG, antiCD2, anti-CD4, and anti-CD8 (Coulter Corp.). The analysis was performed by the flow cytometry facility at State University of New York at Stony Brook using a FACSTAR ${ }^{\oplus}$ Plus (Becton Dickinson and Co., Mountain View, CA).

\section{Results}

Generation and phenotyping of human urushiol-and tetanus toxoid-responsive $T$ cell lines. Using the procedure described above, short-term human $T$ cell lines were generated in response to tetanus toxoid and urushiol. $2 \mathrm{wk}$ after initiation of cultures, the $T$ cells were purified by sheep erythrocyte rosetting and phenotyped for expression of CD3, CD4, and CD8. Tetanus toxoid-responsive lines were uniformly CD3+ CD4+ CD8-, and urushiol-responsive lines were predominantly CD3+ CD8 + (Table I). This was compatible with our previously published reports on urushiol-specific $\mathrm{T}$ cell lines and clones from three individuals (29-31). Several urushiol-specific lines exhibited a significant proportion of double-positive CD4+ CD8+ cells. This has been confirmed with two-color immunofluorescence and reported previously for a urushiolspecific $T$ cell clone (29). Antigen-specific lines from a fourth individual demonstrated similar findings for both urushiol $(\mathrm{CD} 3+98 \% / \mathrm{CD} 4+35 \% / \mathrm{CD} 8+81 \%)$ and tetanus toxoid (CD3+ 93\%/CD4+ 93\%/CD8+ 3\%). Table I demonstrates the predominance of $\mathrm{CD} 8+$ urushiol-specific $\mathrm{T}$ cells for these nine urushiol-specific lines. Since CD4+ and CD8+ cells were purified before use, it was not necessary to determine the phenotype of the unseparated cells, and subsequent $T$ cell lines were not phenotyped.

The predominance of CD8+ urushiol-specific $\mathrm{T}$ cell lines was not an artifact of the culture system since CD4+ CD8-T 
Table I. Phenotype of T Cell Lines

\begin{tabular}{lllll}
\hline \multicolumn{1}{c}{ T cell line } & Neg & CD3 & CD4 & CD8 \\
\hline Urushiol-responsive lines & & & & \\
E18B25 & $5 \% *$ & $99 \%$ & $37 \%$ & $81 \%$ \\
E30B25 & $1 \%$ & $98 \%$ & $26 \%$ & $91 \%$ \\
E149B22 & $3 \%$ & $98 \%$ & $29 \%$ & $84 \%$ \\
E148B22 & $1 \%$ & $96 \%$ & $23 \%$ & $91 \%$ \\
E108B22 & $2 \%$ & $98 \%$ & $41 \%$ & $82 \%$ \\
E89B22 & $2 \%$ & $96 \%$ & $47 \%$ & $79 \%$ \\
E8B22 & $1 \%$ & $98 \%$ & $35 \%$ & $81 \%$ \\
E64B19 & $1 \%$ & $99 \%$ & $13 \%$ & $86 \%$ \\
E60B19 & $1 \%$ & $93 \%$ & $34 \%$ & $87 \%$ \\
Tetanus toxoid-responsive lines & & & & \\
E118B22 & $4 \%$ & $98 \%$ & $95 \%$ & $9 \%$ \\
E89B22 & $1 \%$ & $98 \%$ & $96 \%$ & $4 \%$ \\
E52B22 & $1 \%$ & $99 \%$ & $98 \%$ & $2 \%$ \\
E8B22 & $1 \%$ & $93 \%$ & $93 \%$ & $3 \%$ \\
E64B19 & $4 \%$ & $97 \%$ & $75 \%$ & $8 \%$ \\
\hline
\end{tabular}

Phenotype of $\mathrm{T}$ cell lines was determined by indirect immunofluorescence staining and analysis by flow cytometry. $T$ cell lines were derived independently from the same donor over an interval of 2 yr. * Percentage of positive cells.

cell lines specific for tetanus toxoid were generated from the same donor using the same procedure (Table I). Urushiol specificity was demonstrated by proliferation in response to urushiol but not tetanus toxoid (Table II). T cell lines from the same donor, generated by in vitro stimulation with tetanus toxoid, proliferated in response to tetanus toxoid but not urushiol.

Table II. Antigen Specificity of Urushiol and Tetanus Toxoid Lines

\begin{tabular}{llrrc}
\hline \multicolumn{1}{c}{ Line } & \multicolumn{1}{c}{ Antigen } & Mean & SEM & S.I. \\
\hline Urushiol E63B22 & APC alone & $3155^{*}$ & 142 & Reference \\
& Urushiol & 8037 & 1159 & 2.55 \\
& Tetanus toxoid & 3326 & 145 & 1.05 \\
Urushiol E57B25 & APC alone & 2508 & 796 & Reference \\
& Urushiol & 52031 & 21141 & 20.75 \\
& Tetanus toxoid & 3351 & 1163 & 1.34 \\
Urushiol E61B25 & APC alone & 19537 & 2524 & Reference \\
& Urushiol & 66880 & 15933 & 3.42 \\
Urushiol E106B22 & Tetanus toxoid & 12805 & 3370 & 0.66 \\
& APC alone & 38214 & 13012 & Reference \\
& Urushiol & 96669 & 4240 & 2.53 \\
Tetanus E5B9-3 & Tetanus toxoid & 47566 & 12932 & 1.24 \\
& APC alone & 4358 & 180 & Reference \\
& Urushiol & 5259 & 256 & 1.20 \\
& Tetanus toxoid & 16796 & 640 & 3.80 \\
Tetanus E135B22 & APC alone & 15675 & 3617 & Reference \\
& Urushiol & 10856 & 2334 & 0.69 \\
& Tetanus toxoid & 67830 & 15604 & 4.33 \\
& & & & \\
\hline
\end{tabular}

Cultured $T$ cells were washed and added to proliferation assays (5 $\times 10^{4}$ cells/well) with irradiated autologous PBMC (APC) $\left(1 \times 10^{5}\right.$ cells/well) and antigen as designated. $\left[{ }^{3} \mathrm{H}\right]$ Thymidine was added to the wells at $24 \mathrm{~h}$, and cells were harvested $18 \mathrm{~h}$ later. * Proliferation in dpm. S.I., stimulation index.
After purification by sheep red blood cell rosetting, $\mathrm{T}$ cell lines demonstrated levels of staining below background (1\%) with markers for macrophages (MO1) and B cells (B1). Staining for the $\gamma / \delta$ T cell receptor (T cell receptor- $\delta 1$ ) was also negative. Urushiol $\mathrm{T}$ cell lines depleted of CD4+ cells with magnetic particles contained $>95 \%$ CD8 + cells and $<3 \%$ CD4+ cells. The CD8+-depleted urushiol-responsive cell lines contained $<9 \%$ CD8+ cells.

Antigen processing requirements for urushiol: (antigen pulse/fix) vs (fix/antigen pulse). The requirement for processing of urushiol by APC was studied by replicating classic ( fix / pulse) vs (pulse/fix) experiments $(36,37)$. This required the use of paraformaldehyde-fixed APC. Anti-CD28 has been shown to reconstitute the response of human $\mathrm{CD} 4+\mathrm{T}$ cells to tetanus toxoid presented by fixed APC (38). We have found that anti-CD28 also allows fixed PBMC to present urushiol to human urushiol-specific CD8+ T cells (39). For this reason, anti-CD28 (1:500 ascites) was added to cultures in which fixed erythrocyte rosette negative fraction [ $(\mathrm{E}-)$ cells] functioned as APC.

APC were incubated with urushiol $(1 \mu \mathrm{g} / \mathrm{ml})$ for $1 \mathrm{~h}$ at $37^{\circ} \mathrm{C}$ either before or after fixation with paraformaldehyde. Control fixed APC were not exposed to urushiol. Fixed APC were then added to purified CD4+ or CD8+ urushiol-responsive cultured $T$ cells, and $T$ cell proliferation was measured by $\left[{ }^{3} \mathrm{H}\right]$ thymidine uptake. Experiments were performed with both autologous (E-) and EBV817 cells as APC. When fixed autologous (E-) cells were used as APC, anti-CD28 ascites were added at 1:500 dilution. Autologous EBV transformed B cells (EBV817) were not dependent on anti-CD28 for antigen presentation as EBV transformed $B$ cells express a high constitutive level of B7/BB1 (38).

The antigen processing requirements for presentation to CD8 $+\mathrm{T}$ cells exhibited heterogeneity (Figs. 1 and 2). Certain CD8 $+\mathrm{T}$ cells proliferated optimally if the urushiol was presented by APC incubated with urushiol before fixation (Fig. 1, URUSHIOL/FIX). APC that were fixed before incubation with urushiol (Fig. 1, FIX/URUSHIOL) were less effective at presenting urushiol to these $\mathrm{T}$ cells. These $\mathrm{CD} 8+\mathrm{T}$ cells required processing of the urushiol by a viable APC. Fixation with $0.12 \%$ paraformaldehyde for $5 \mathrm{~min}$ was found to reduce $\left[{ }^{3} \mathrm{H}\right]$ leucine uptake of APC to the level of uptake in the presence of $1 \%$ azide ( Table III), confirming the lack of viability of the fixed cells. Processing dependence of CD8+ cells was demonstrated both with autologous (E-) and EBV817 cells as $\mathrm{APC}$.

Processing-independent CD8 $+\mathrm{T}$ cells were also detected. These CD8+ cells were able to recognize APC incubated with urushiol after fixation (Fig. 2, FIX/URUSHIOL). Since processing by viable APC was not required, these CD8+ cells may recognize urushiol either conjugated directly to the MHC class I molecule or to a peptide in the antigen-presenting groove of the MHC class I. Similar results were observed whether (E-) or EBV817 cells were used as APC. Omission of anti-CD28 from these cultures abrogated the proliferative response to urushiol when ( $\mathrm{E}-$ ) cells were used as APC (data not shown). This indicates that urushiol was indeed presented by the fixed APC.

Cloned CD8+ urushiol-specific T cells recognized urushiol independent of processing ( Table IV). Apparently, in vitro restimulation with urushiol under the culture conditions selected for processing independent CD8+ cells. The response of these $\mathrm{T}$ cell clones to fix/urushiol frequently exceeded the response 


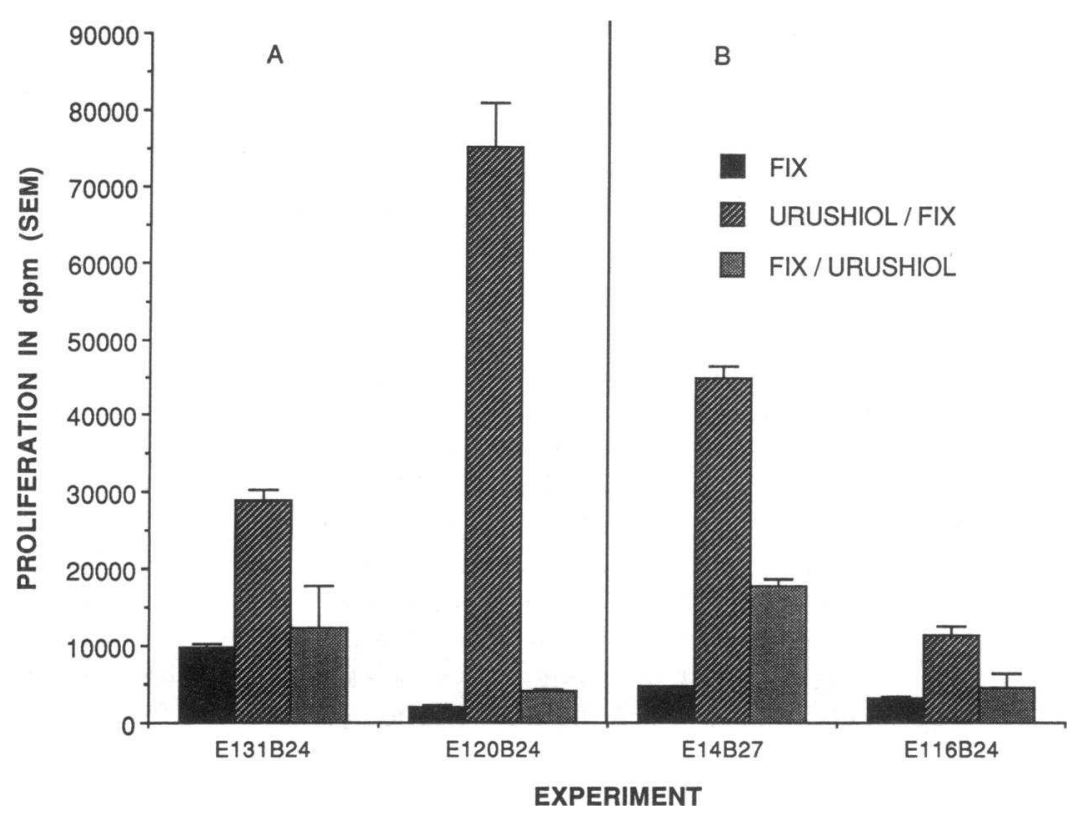

Figure 1. Presentation of urushiol to processingdependent $\mathrm{CD} 8+\mathrm{T}$ cells by paraformaldehydefixed APC. $A$, Autologous (E-) cells as APC. $B$, Autologous EBV transformed B cells (EBV817) as APC. APC were incubated for $1 \mathrm{~h}$ with urushiol $(1 \mu \mathrm{g} / \mathrm{ml}$ ) either before (URUSHIOL $/ F I X)$ or after (FIX/URUSHIOL) fixation with paraformaldehyde. Control APC were fixed without exposure to urushiol $(F I X)$. Anti-CD28 (ascites $1: 500$ ) was included in the final culture medium when (E-) cells were used as APC. Error bars designate SEM. T cell lines used are designated by numbers. $T$ cell lines were often used for the purification of both CD8+ and CD4+ cells on the same day, as represented by the same number designation in Figs. 1-3. to urushiol/fix. It is likely that paraformaldehyde fixation promotes cross-linking of urushiol with the cell surface and thereby facilitates presentation of urushiol to processing-independent cells.

CD4+ urushiol-responsive $T$ cells were found to be processing dependent (Fig. 3). APC that had been incubated with urushiol before fixation (Fig. 3, URUSHIOL/FIX) were able to induce proliferation. However, fixation of APC before urushiol incubation (Fig. 3, FIX/URUSHIOL) abrogated the ability of the CD4+ cells to respond. Similar data were obtained whether (E-) or EBV817 cells were used as APC. CD4+ cells purified from line E131B24 were tested against both (E-) and EBV817 cells as APC on the same day with similar results. CD8+ cells purified from this same line were also tested against (E-) cells as APC (Fig. 1).
Processing of urushiol for presentation to $C D 8+T$ cells was sensitive to monensin and brefeldin $A$. Inhibitors of antigen processing were used to characterize the processing requirements of urushiol for presentation to CD8+ cells. APC were preincubated with monensin or brefeldin $A$ for $1 \mathrm{~h}$ at $37^{\circ} \mathrm{C}$ before addition of urushiol for a 1-h incubation. The APC were then fixed with paraformaldehyde and used as stimulators in proliferation assays with $\mathrm{CD} 8+$ urushiol-responsive $\mathrm{T}$ cells. Maximal $\mathrm{T}$ cell proliferation was determined from the response to APC incubated with urushiol in the absence of inhibitors.

Presentation of urushiol to cultured CD8 $+\mathrm{T}$ cells by either (E-) or EBV817 cells was inhibited by monensin and brefeldin A (Table V). This strongly suggests that processing was dependent upon transport from the endoplasmic reticulum. In con-

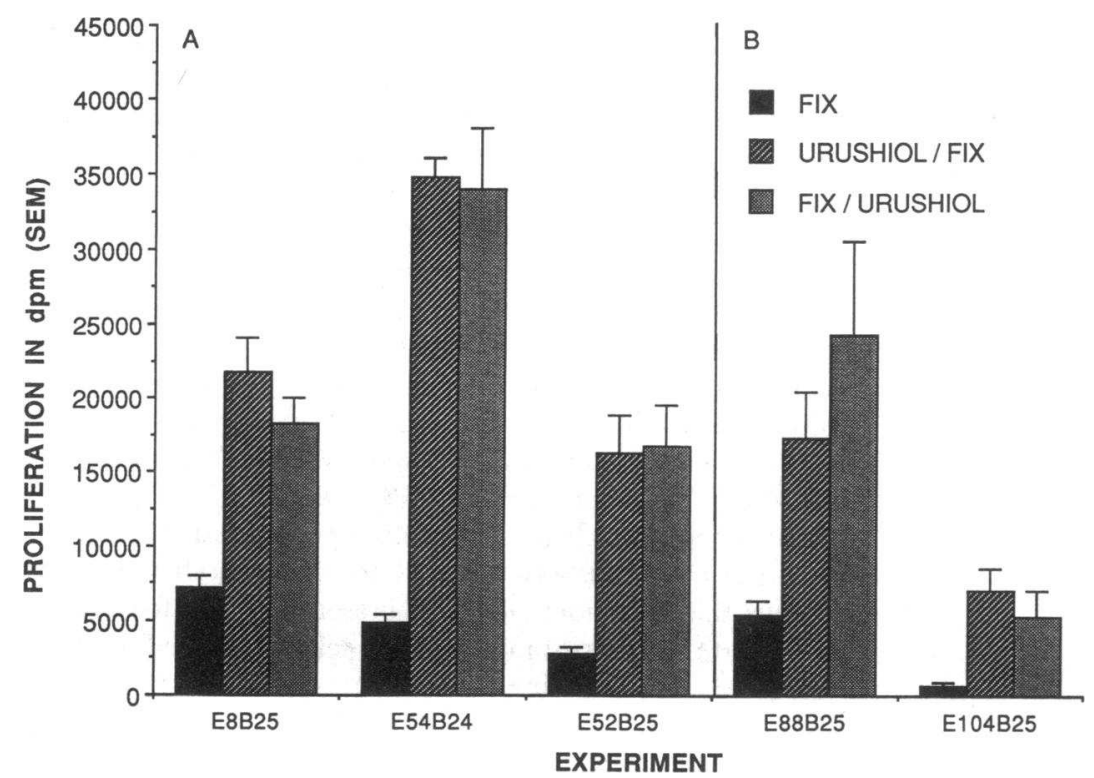

Figure 2. Presentation of urushiol to processing-independent CD8 $+\mathrm{T}$ cells by paraformaldehyde-fixed APC. $A$, Autologous (E-) cells as APC. B, Autologous EBV transformed B cells (EBV817) as APC. APC were incubated for $1 \mathrm{~h}$ with urushiol $(1 \mu \mathrm{g} / \mathrm{ml})$ either before (URU$S H I O L / F I X)$ or after (FIX/URUSHIOL) fixation with paraformaldehyde. Control APC were fixed without exposure to urushiol $(F I X)$. 
Table III. $\left[{ }^{3} \mathrm{H}\right]$ Leucine Uptake after Fixation

\begin{tabular}{lcr}
\hline Treatment & Mean dpm & SEM \\
\hline EBV817 cells & & \\
Not fixed & $15,117^{*}$ & 1,280 \\
Fix 2 min & 1,067 & 95 \\
Fix 5 min & 914 & 73 \\
Fix 10 min & 875 & 72 \\
Fix 20 min & 1,285 & 220 \\
1\% Azide & 1,078 & 104 \\
(E-) cells & & \\
Alone; not fixed & 5,936 & 1,127 \\
Fixed 2 min & 1,578 & 133 \\
Fixed 5 min & 1,565 & 221 \\
Fixed 10 min & 1,778 & 117 \\
& & \\
\hline
\end{tabular}

$\left[{ }^{3} \mathrm{H}\right]$ Leucine uptake by $2 \times 10^{5}$ cells/well (EBV817) or $4 \times 10^{5}$ cells/ well (E-) cells during a $15-\mathrm{h}$ incubation was determined after fixation of the cells with paraformaldehyde for varying lengths of time or treatment with $1 \%$ azide.

trast, none of these inhibitors altered presentation of urushiol to processing-independent $\mathrm{CD} 8+\mathrm{T}$ cell lines ( Table VI). This serves as a negative control for the inhibitors since processing was not required for presentation to these $T$ cells.

Processing of urushiol for presentation to CD4+T cells was sensitive to monensin but not brefeldin A. Presentation of urushiol by either (E-) or EBV817 cells to cultured CD4+ T cells was inhibited by monensin but not brefeldin A (Table VII). The lack of inhibition by brefeldin A along with the inhibition by monensin was consistent with the processing of urushiol by the endosomal pathway for presentation to CD4+ cells by class II MHC.

Processing of tetanus toxoid for presentation to CD4+ cells was inhibited by monensin but not by brefeldin $A$. Tetanus toxoid-specific $\mathrm{T}$ cell lines derived from the same donor were used
Table IV. Antigen Processing Independence of CD8+ Urushiol-specific T Cell Clones

\begin{tabular}{llcl}
\hline \multicolumn{1}{c}{ Clone } & \multicolumn{1}{c}{ Fix } & Urushiol/fix & Fix/urushiol \\
\hline $74 B 25-18$ & $62^{*}(11)$ & $185(5)$ & $148(2)$ \\
$74 B 25-9$ & $42(2)$ & $12(0.1)$ & $143(0.1)$ \\
R28B1 & $48(7)$ & $51(7)$ & $168(86)$ \\
R31-3B2-5 & $49(4)$ & $45(4)$ & $125(8)$ \\
\hline
\end{tabular}

* Proliferation in dpm $\times 10^{-2}$. Numbers in parentheses represent SEM.

as a positive control for the antigen processing assay. APC were incubated with inhibitors for $1 \mathrm{~h}$, then incubated with tetanus toxoid for $1 \mathrm{~h}$ and fixed as above.

Monensin was able to inhibit processing of tetanus toxoid. However, brefeldin A was not inhibitory under these conditions ( Table VIII). These data further confirm the specificity of brefeldin A for the endogenous pathway of antigen processing under these conditions.

Azide-inhibited processing of urushiol for presentation to $C D 8+$ cells but not $C D 4+$ cells. APC were incubated with azide for $1 \mathrm{~h}$ before addition of urushiol for a second $1-\mathrm{h}$ incubation as above. APC were then fixed, washed, and tested for their ability to present urushiol to both CD4+ and CD8+ urushiolresponsive $\mathrm{T}$ cells.

Azide treatment under these conditions inhibited the ability to process urushiol for presentation to CD8+ cells but not CD4+ cells (Table IX). This suggests that processing of urushiol for presentation to CD8+ cells was dependent upon oxidative cell metabolism.

\section{Discussion}

Three alternative routes were defined by which urushiol can be presented to human $T$ cells. CD8 $+T$ cells recognized urushiol processed by the endogenous antigen processing pathway.

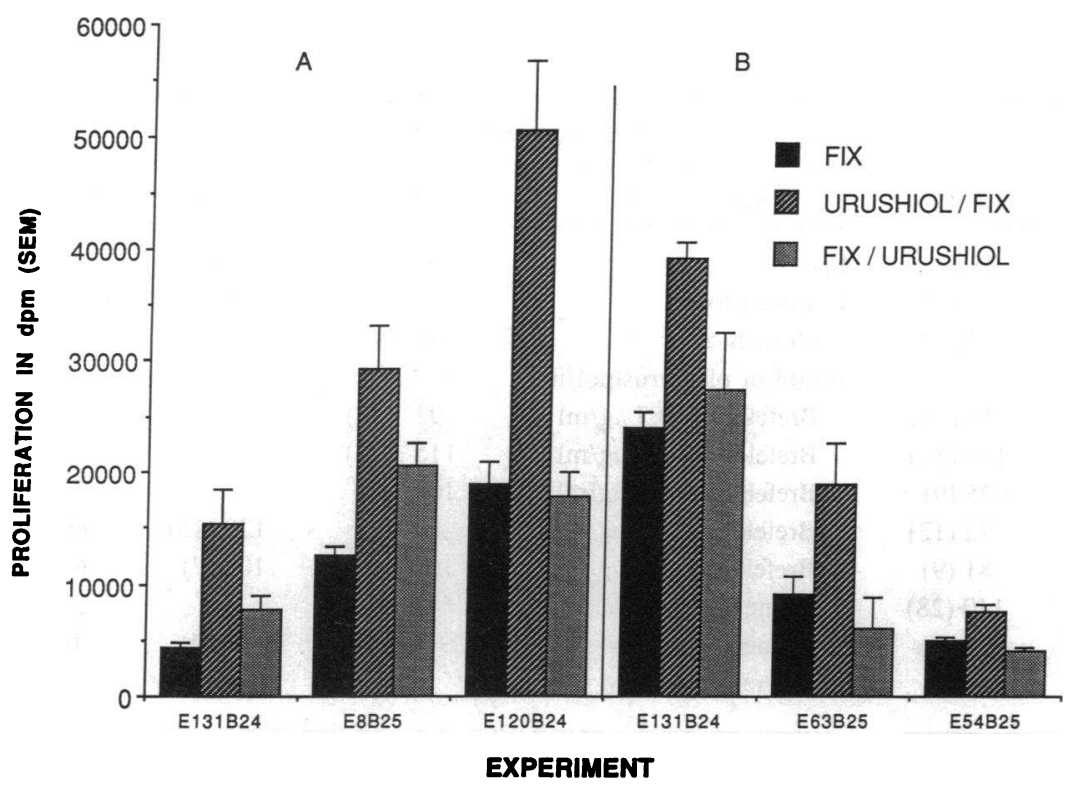

Figure 3. Presentation of urushiol to CD4+ T cells by paraformaldehyde-fixed APC. $A$, Autologous (E-) cells as APC. $B$, Autologous EBV transformed B cells (EBV817) as APC. APC were incubated for $1 \mathrm{~h}$ with urushiol $(1 \mu \mathrm{g} / \mathrm{ml})$ either before (URUSHIOL/FIX) or after (FIX/URU$S H I O L$ ) fixation with paraformaldehyde. Control APC were fixed without exposure to urushiol (FIX). The CD4+ line E131B24 was tested the same day against both (E-) and EBV817 cells. 
Table V. Effects of Brefeldin A and Monensin on Processing of Urushiol for Presentation to CD8+T Cells

\begin{tabular}{|c|c|c|c|c|}
\hline Treatment of APC & E57B27 & E116B24 & E30B25 & E120B24 \\
\hline Fix & $288^{*}(25)$ & $32(2)$ & $150(7)$ & $97(6)$ \\
\hline Urushiol/fix & 744 (33) & $114(17)$ & $233(14)$ & 289 (14) \\
\hline Fix/urushiol & $566(48)$ & $44(8)$ & $102(7)$ & $122(22)$ \\
\hline \multicolumn{5}{|l|}{ Inhibitor plus urushiol/fix } \\
\hline Brefeldin A $0.5 \mu \mathrm{g} / \mathrm{ml}$ & $597 \quad(24)$ & & & \\
\hline Brefeldin A $1.0 \mu \mathrm{g} / \mathrm{ml}$ & 403 (29) & & & \\
\hline Brefeldin A $2.0 \mu \mathrm{g} / \mathrm{ml}$ & 445 (29) & & & \\
\hline Brefeldin A $4.0 \mu \mathrm{g} / \mathrm{ml}$ & $384(45)$ & $102(20)$ & $219(11)$ & $256(22)$ \\
\hline Brefeldin A $8.0 \mu \mathrm{g} / \mathrm{ml}$ & $387 \quad(44)$ & $55(55)$ & $175(15)$ & $192(35)$ \\
\hline Monensin $1.0 \mu \mathrm{M}$ & $848 \quad(73)$ & & & \\
\hline Monensin $2.0 \mu \mathrm{M}$ & $730 \quad(62)$ & & & \\
\hline Monensin $4.0 \mu \mathrm{M}$ & 529 (19) & $42(47)$ & $165(12)$ & $145(19)$ \\
\hline Monensin $8.0 \mu \mathrm{M}$ & 490 (49) & $31(2)$ & $144(14)$ & $129(16)$ \\
\hline
\end{tabular}

APC were incubated with urushiol for $1 \mathrm{~h}$ either before (Urushiol/fix) or after (Fix/urushiol) fixation with paraformaldehyde. Control APC were fixed without exposure to urushiol (Fix). The effects of inhibitors on antigen processing were tested by incubating APC with inhibitors as indicated for $1 \mathrm{~h}$, urushiol was then added for a 1-h incubation, and the APC were fixed. Cultured T cells were added to the urushiol-treated APC, and proliferation was determined by $\left[{ }^{3} \mathrm{H}\right]$ thymidine uptake after a $24-\mathrm{h}$ incubation. Groups consisted of replicates of six wells. SEM shown in parentheses. * Proliferation in $\mathrm{dpm} \times 10^{-2}$.

CD4+ T cells recognized urushiol processed by the exogenous, endosome-dependent antigen processing pathway. Urushiol conjugated to extracellular proteins ("extracellular hapten") should be processed in this manner. Finally, certain CD8+ cells recognized urushiol without processing. This implies recognition of urushiol directly conjugated to either the MHC class I molecule or a peptide in the antigen-binding groove. These processing alternatives were supported by (fix/antigen) vs (antigen / fix) experiments and inhibitor studies. Lack of inhibition of presentation to processing-independent $T$ cells by either inhibitor provided a negative control for the processing assay. Inhibition of processing of tetanus toxoid by monensin but not brefeldin A demonstrated the specificity of brefeldin A for the exogenous pathway under these conditions.

Recognition of urushiol by certain CD8+ cells in the ab-

Table VI. Lack of Effect of Processing Inhibitors on Presentation of Urushiol to Processing-independent CD8+T Cells

\begin{tabular}{|c|c|c|c|}
\hline Treatment of APC & E63B24 & E61B25 & E49B24 \\
\hline Fix & $143 *(7)$ & $22(7)$ & $28(7)$ \\
\hline Urushiol/fix & $575(24)$ & $133(17)$ & $73(16)$ \\
\hline Fix/urushiol & 694 (19) & $122(17)$ & 77 (17) \\
\hline \multicolumn{4}{|l|}{ Inhibitor plus urushiol/fix } \\
\hline Brefeldin A $1.0 \mu \mathrm{g} / \mathrm{ml}$ & & & $59(18)$ \\
\hline Brefeldin A $2.0 \mu \mathrm{g} / \mathrm{ml}$ & & $162(19)$ & $113(11)$ \\
\hline Brefeldin A $4.0 \mu \mathrm{g} / \mathrm{ml}$ & $618(53)$ & $130(12)$ & $75(9)$ \\
\hline Brefeldin A $8.0 \mu \mathrm{g} / \mathrm{ml}$ & $695 \quad(32)$ & $179(17)$ & $72(12)$ \\
\hline Monensin $1.0 \mu \mathrm{M}$ & 723 & & $81(9)$ \\
\hline Monensin $2.0 \mu \mathrm{M}$ & $620(66)$ & & $140(28)$ \\
\hline Monensin $4.0 \mu \mathrm{M}$ & $699(20)$ & $161(12)$ & $91(7)$ \\
\hline Monensin $8.0 \mu \mathrm{M}$ & & $112(12)$ & \\
\hline
\end{tabular}

* Proliferation in $\mathrm{dpm} \times 10^{-2}$. SEM shown in parentheses. sence of processing suggested that urushiol can directly conjugate either the MHC class I molecule or a peptide in the binding groove. However, urushiol is not a superantigen. Only urushiol-specific $\mathrm{T}$ cell lines responded to urushiol. Tetanus toxoid-specific $\mathrm{T}$ cell lines from the same donor were not urushiol responsive. Furthermore, only $\mathrm{T}$ cells from persons with a history of urushiol (poison ivy) sensitivity are responsive to urushiol in vitro (40). Finally, the frequency of urushiol-responsive cells in peripheral blood is generally $<1: 5,000$ (31), which is not compatible with a superantigen response.

These results were obtained with a number of short-term $T$ cell lines. Cloned CD8 + urushiol-specific T cells were independent of processing. This may be an artifact of the conditions of in vitro restimulation with urushiol since short-term lines were predominantly dependent upon processing. Both EBV trans-

Table VII. Effects of Brefeldin A and Monensin on Processing of Urushiol for Presentation to CD4+T Cells

\begin{tabular}{lccc}
\hline \multicolumn{1}{c}{ Treatment of APC } & E40B27 & E116B24 & E54B24 \\
\hline Fix & $50^{*}(7)$ & $60(12)$ & $49(4)$ \\
Urushiol/fix & $96(15)$ & $114(20)$ & $77(7)$ \\
Fix/urushiol & $64(9)$ & $40(3)$ & \\
Inhibitor plus urushiol/fix & & & \\
Brefeldin A 0.5 $\mu \mathrm{g} / \mathrm{ml}$ & $92(13)$ & & \\
Brefeldin A 1.0 $\mu \mathrm{g} / \mathrm{ml}$ & $115(23)$ & & $62(2)$ \\
Brefeldin A 2.0 $\mu \mathrm{g} / \mathrm{ml}$ & $106(5)$ & & $60(2)$ \\
Brefeldin A 4.0 $\mu \mathrm{g} / \mathrm{ml}$ & $87(9)$ & $120(15)$ & $69(3)$ \\
Brefeldin A $8.0 \mu \mathrm{g} / \mathrm{ml}$ & $108(6)$ & $100(7)$ & $50(3)$ \\
Monensin 2.0 $\mu \mathrm{M}$ & & & $48(5)$ \\
Monensin 4.0 $\mu \mathrm{M}$ & & $66(4)$ & $39(2)$ \\
Monensin 8.0 $\mu \mathrm{M}$ & & $40(20)$ &
\end{tabular}

* Proliferation in $\mathrm{dpm} \times 10^{-2}$. SEM shown in parentheses. 
Table VIII. Effects of Brefeldin A and Monensin on Processing of Tetanus Toxoid for Presentation to CD4+ TCells

\begin{tabular}{|c|c|c|c|}
\hline Treatment of APC & E135B22 & E118B22 & E89B22 \\
\hline Fix & $70^{*}(9)$ & $26(2)$ & $36(4)$ \\
\hline Urushiol/fix & $130(16)$ & $291(10)$ & $72(5)$ \\
\hline Fix/Urushiol & $81(7)$ & ND & ND \\
\hline \multicolumn{4}{|l|}{ Inhibitor plus urushiol/fix } \\
\hline Brefeldin A $0.5 \mu \mathrm{g} / \mathrm{ml}$ & $158(9)$ & $361(6)$ & $69(10)$ \\
\hline Brefeldin A $1.0 \mu \mathrm{g} / \mathrm{ml}$ & $195(27)$ & & $64(10)$ \\
\hline Brefeldin A $2.0 \mu \mathrm{g} / \mathrm{ml}$ & & $341(11)$ & \\
\hline Brefeldin A $4.0 \mu \mathrm{g} / \mathrm{ml}$ & $195(27)$ & & \\
\hline Brefeldin A $8.0 \mu \mathrm{g} / \mathrm{ml}$ & $158(13)$ & & \\
\hline Monensin $1.0 \mu \mathrm{M}$ & & & $59(6)$ \\
\hline Monensin $2.0 \mu \mathrm{M}$ & & $242(11)$ & $49(5)$ \\
\hline Monensin $4.0 \mu \mathrm{M}$ & & $97(11)$ & \\
\hline
\end{tabular}

* Proliferation in $\mathrm{dpm} \times 10^{-2}$. SEM shown in parentheses.

formed B cells and peripheral blood $(\mathrm{E}-$ ) cells were used as APC with similar results. Thus, these findings relate to both types of APC.

Monensin is a sodium ionophore that interferes with both endosomal function (12) and transport of proteins from the golgi complex $(25)$ by collapsing proton gradients $(41,42)$. The ability of monensin to interfere with golgi complex function has been overlooked in the immunology literature. This interference with transport from the golgi complex can explain the ability of monensin to inhibit presentation to CD8+ cells. Monensin inhibits endosomal/lysosomal antigen processing by preventing acidification of lysosomes. Chloroquine also inhibits endosomal antigen processing by raising intralysosomal pH (43).

Brefeldin A inhibition of processing indicates that transport from the endoplasmic reticulum was required for presentation

Table IX. Effects of Azide on Processing of Urushiol for Presentation to CD4+ or CD8+ TCells

\begin{tabular}{lrlrr}
\hline Experiment & \multicolumn{1}{c}{ Fix } & Urushiol/fix & Fix/urushiol & Azide 0.5\% \\
\hline CD4+ T cells & & & & \\
E116B24 & $60^{*}(12)$ & $114(20)$ & $91(23)$ & $132(15)$ \\
E131B24 & $44(4)$ & $153(32)$ & $78(13)$ & $123(18)$ \\
E120B24 & $189(20)$ & $506(62)$ & $179(21)$ & $449(32)$ \\
CD8+ T cells & & & & \\
E54B25 & $20(2)$ & $106(26)$ & $69(14)$ & $53(12)$ \\
E116B24 & $32(2)$ & $114(11)$ & $44(8)$ & $58(9)$ \\
E30B25 & $150(7)$ & $233(14)$ & $102(7)$ & $146(9)$ \\
E131B24 & $97(6)$ & $290(14)$ & $123(22)$ & $120(6)$
\end{tabular}

APC were incubated with azide for $1 \mathrm{~h}$ before addition of urushiol for $1 \mathrm{~h}$. APC were then fixed with paraformaldehyde. Control APC were either not exposed to urushiol (Fix), incubated with urushiol before fixation (Urushiol/fix), or incubated with urushiol after fixation (Fix/urushiol). Cultured T cells were added, and proliferation was determined by $\left[{ }^{3} \mathrm{H}\right]$ thymidine uptake after $24 \mathrm{~h}$. Replicates of six wells were used for each group, and SEM is shown in parentheses.

* Proliferation in dpm $\times 10^{-2}$. to $\mathrm{CD} 8+$ cells $(26,27)$. When added for a sufficient period of time, brefeldin A can also inhibit presentation of exogenous antigens on MHC class II on the basis of inhibition of transport of newly synthesized MHC class II molecules (44). However, when brefeldin A was present for a total of $2 \mathrm{~h}$, the presentation of tetanus toxoid or urushiol to CD4 $+\mathrm{T}$ cells was not inhibited, indicating a selectivity for the exogenous pathway of antigen processing under these conditions. The lack of inhibition of processing of tetanus toxoid is an important control for the specificity of brefeldin A action, since tetanus toxoid is an exogenous protein which should be processed by the exogenous pathway. An additional negative control was provided by the inability of either monensin or brefeldin A to inhibit presentation of urushiol to the processing-independent $\mathrm{CD} 8+$ urushiolspecific lines.

The predominance of $\mathrm{CD} 8+$ urushiol-specific $\mathrm{T}$ cell lines and clones in the urushiol response (29-31) implies that urushiol was presented primarily on MHC class I molecules. It is hypothesized that urushiol becomes oxidized to an active quinone derivative intracellularly. The respiratory burst or reactive oxygen species (6) generated by mitochondria may have a role in oxidizing urushiol. Azide, an inhibitor of oxidative respiration, was able to preferentially inhibit presentation of urushiol to $\mathrm{CD} 8+$ cells under the experimental conditions. The quinone intermediate produced by oxidation of urushiol may conjugate cytoplasmic proteins. These conjugated cytoplasmic proteins would then be processed by the endogenous pathway for presentation on MHC class I molecules to CD8+ cells.

Processing of urushiol by the endogenous antigen presentation pathway may explain discrepancies in the literature on allergic contact dermatitis. Certain allergens, such as nickel and cobalt, evoke a pure CD4+ response $(45,46)$. Other allergens such as DNFB evoke a combined CD4+ and CD8+ response (32). Urushiol, in contrast, evokes a predominantly CD8+ response (29-31). It is proposed that nickel and cobalt are extracellular haptens that associate with proteins extracellularly. These extracellular proteins are subsequently internalized and processed by the exogenous pathway for presentation to CD4+ cells. Urushiol may function as an "intracellular hapten" and may conjugate cytoplasmic proteins for subsequently degradation and presentation by the endogenous pathway to CD8+ cells. Small chemically reactive lipid-soluble molecules such as DNFB and urushiol should be both capable of conjugating extracellular proteins and penetrating cell membranes to conjugate intracellular proteins. As predicted by this theory, DNFB evokes a mixed CD4+ and CD8+ response (32).

There is additional evidence that $T$ cells recognize haptens on processed peptides. Trinitrophenol (TNP)-specific murine $T$ cell clones recognize TNP conjugated to peptides (47). The recognition of the TNP peptides is dependent upon the position of TNP within the peptide rather than the peptide sequence (48). Provided the ability to bind MHC class I ( $\mathrm{H}-$ $2 \mathrm{~K}^{\mathrm{b}}$ ) was retained and the TNP was located on the fourth amino acid residue, $T$ cell clones recognized a variety of peptides with varying sequence. Recognition of TNP could be blocked by anti-TNP antibody, suggesting TNP was oriented outward in the MHC peptide groove. Recognition of TNP peptide by murine $T$ cell clones has been mapped to preferential use of specific $\mathrm{V}$ and $\mathrm{J}$ junctional regions (49). Nickel also binds to peptides bound to MHC antigens, possibly through histidine residues. Nickel can bind to preprocessed peptides on 
fixed APC (50), indicating that processing is not necessary if the hapten binds to preprocessed peptide.

This proposed classification of haptens into intracellular and extracellular haptens may have relevance to conditions other than allergic contact dermatitis. Certain drugs such as sulfonamides (51) and phenytoin (52) are metabolized into chemically reactive forms intracellularly. It is predicted that these drugs would also function as intracellular haptens and the $T$ cell response to these drugs in patients with drug eruptions would be mediated by CD8+ cells. This is supported by the isolation of $\mathrm{CD} 8+\mathrm{T}$ cells specific for sulfonamide (53) and penicillin (54) from bullous drug eruptions.

Three mechanisms for processing and presentation of urushiol were delineated. Urushiol could act as an intracellular hapten and be processed by the endogenous pathway for presentation to CD8 + T cells. Presentation to CD4+ T cells followed processing by the exogenous pathway (extracellular hapten). Finally, certain CD8 $+\mathrm{T}$ cell lines were found to recognize urushiol without processing, presumably after direct conjugation to either MHC class I molecules or peptides in the antigenpresenting groove. This classification of haptens by presentation pathway may explain the differential response of CD4+ and $C D 8+T$ cells to various haptens and may provide a framework for understanding allergic contact dermatitis.

\section{Acknowledgments}

We thank Dr. David Volkman for his helpful discussions and review of the manuscript and Dr. Chikao Morimoto for the generous donation of monoclonal antibodies. Cytofluorograph analysis was expertly performed by James M. Simone.

This work was funded in part by National Institutes of Health grant AI-26580.

\section{References}

1. Baer, H. 1986. Chemistry and immunology of poisonous Anacardiaceae Clinics in Dermatology. 4:152-159.

2. Kligman, A. M. 1958. Poison ivy (Rhus) dermatitis. Arch. Dermatol. 77:149-180

3. Dawson, C. R. 1956. The chemistry of poison ivy. Trans. NY Acad. Sci. 18:427-443.

4. Billets, S., J. C. Craig, M. D. Corbett, and J. F. Vickery. 1976. Component analysis of the urushiol content of poison ivy and poison oak. Phytochemistry (Oxf.). 15:533-535.

5. Byck, J. S., and C. R. Dawson. 1968. Assay of protein-quinone coupling involving compounds structurally related to the active principle of poison ivy. Anal. Biochem. 25:123-135.

6. Schmidt, R. J., L. Khan, and L. Y. Chung. 1990. Are free radicals and not quinones the haptenic species derived from urushiol and other contact allergenic mono- and dihydric alkylbenzenes? The significance of NADH, glutathione, and redox cycling in the skin. Arch. Dermatol. Res. 282:56-64.

7. Germain, R. N. 1986. The ins and outs of antigen processing and presentation. Nature (Lond.). 322:687-689.

8. Sweetser, M. T., L. A. Morrison, V. L. Braciale, and T. J. Braciale. 1989. Recognition of pre-processed endogenous antigen by class I but not class II MHCrestricted T cells. Nature (Lond.). 342:180-182.

9. Nuchtern, J. G., J. S. Bonifacino, W. E. Biddison, and R. D. Klausner. 1989. Brefeldin A implicates egress from endoplasmic reticulum in class I restricted antigen presentation. Nature (Lond.). 339:223-225.

10. Teyton, L., D. O'Sullivan, P. W. Dickson, V. Lotteau, A. Sette, P. Fink, and P. A. Peterson. 1990. Invariant chain distinguishes between the exogenous and endogenous antigen presentation pathways. Nature (Lond.). 348:39-44.

11. Ziegler, H. K., and E. R. Unanue. 1982. Decrease in macrophage antigen catabolism caused by ammonia and chloroquine is associated with inhibition of antigen presentation to T cells. Proc. Natl. Acad. Sci. USA. 79:175-178.

12. Bauer, A., I. Rutenfranz, and H. Kirchner. 1988. Processing requirements for T cell activation by Mycoplasma arthridis-derived mitogen. Eur. J. Immunol. 18:2109-2112.
13. Michalek, M. T., B. Benacerraf, and K. L. Rock. 1992. The class II MHCrestricted presentation of endogenously synthesized ovalbumin displays clonal variation, requires endosomal/lysosomal processing, and is up-regulated by heat shock. J. Immunol. 148:1016-1024.

14. Hunt, D. F., H. Michel, T. A. Dinckinson, J. Shabanowitz, A. L. Cox, K. Sakaguchi, E. Appella, H. M. Grey, and A. Sette. 1992. Peptides presented to the immune system by the murine class II major histocompatibility complex molecule I-A ${ }^{\mathrm{d}}$. Science (Wash. DC). 256:1817-1820.

15. Yang, Y., J. B. Waters, K. Fruh, and P. A. Peterson. 1992. Proteasomes are regulated by interferon gamma: implications for antigen processing. Proc. Natl. Acad. Sci. USA. 89:4928-4932.

16. Kelly, A., S. H. Powis, R. Glynne, E. Radley, S. Beck, and J. Trowsdale. 1991. Second proteasome-related gene in the human MHC class II region. Nature (Lond.). 353:6678-6680.

17. Martinez, C. K., and J. J. Monaco. 1991. Homology of proteasome subunits to a major histocompatibility complex-linked LMP gene. Nature (Lond.). 353:664-667.

18. Attaya, M., S. Jameson, C. K. Martinez, E. Hermel, C. Aldrich, J. Forman, K. F. Lindahl, M. J. Bevan, and J. J. Monaco. 1992. Ham-2 corrects the class I antigen processing defect in RMA-S cells. Nature (Lond.). 355:647-649.

19. Spies, T., M. Bresnahan, S. Bahram, D. Arnold, G. Blanck, E. Mellins, D. Pious, and R. DeMars. 1990. A gene in the human major histocompatibility complex class II region controlling the class I antigen presentation pathway. $\mathrm{Na}$ ture (Lond.). 348:744-747.

20. Spies, T., V. Cerundolo, M. Colonna, P. Cresswell, A. Townsend, and R. DeMars. 1992. Presentation of viral antigen by MHC class I molecules is dependent on a putative peptide transporter heterodimer. Nature (Lond.). 355:644646.

21. Colonna, M., M. Bresnahan, S. Bahram, J. L. Strominger, and T. Spies. 1992. Allelic variants of the human putative peptide transporter involved in antigen processing. Proc. Natl. Acad. Sci. USA. 89:3932-3936.

22. Cresswell, P., and M. L. Wei. 1992. HLA-A2 molecules in an antigen processing mutant contain signal sequence-derived peptides. Nature (Lond.). 356:443-446.

23. Crumpacker, D. B., J. Alexander, P. Cresswell, and V. H. Engelhard. 1992. Role of endogenous peptides in murine allogeneic cytotoxic $\mathrm{T}$ cell responses assessed in using transfectants of the antigen-processing mutant 174XCEM.T2. J. Immunol. 148:3004-3011.

24. Cox, J. H., J. W. Yewdell, L. C. Eisenlohr, P. R. Johnson, and J. R. Bennink. 1990. Antigen presentation requires transport of MHC class I molecules from the endoplasmic reticulum. Science (Wash. DC). 247:715-718.

25. Ledger, P. W., and M. L. Tanzer. 1984. Monensin - a perturbant of cellular physiology. Trends Pharmacol. Sci. 5:313-314.

26. Lippincott-Schwartz, J., L. C. Yuan, J. S. Bonifacino, and R. D. Klausner. 1989. Rapid redistribution of golgi proteins into the ER in cells treated with brefeldin A: evidence for membrane cycling from golgi to ER. Cell. 56:801-813.

27. Yewdell, J. W., and J. R. Bennink. 1989. Brefeldin A specifically inhibits presentation of protein antigens to cytotoxic T lymphocytes. Science (Wash. DC). 244:1072-1075.

28. Michalek, M. T., B. Benacerraf, and K. L. Rock. 1992. The class II MHCrestricted presentation of endogenously synthesized ovalbumin displays clonal variation, requires endosomal/lysosomal processing, and is up-regulated by heat shock. J. Immunol. 148:1016-1024.

29. Kalish, R. S., and C. Morimoto. 1988. Urushiol (poison ivy)-triggered suppressor T cell clone generated from peripheral blood. J. Clin. Invest. 82:825832.

30. Kalish, R. S., and C. Morimoto. 1989. Quantitation and cloning of human urushiol specific peripheral blood T-cells: isolation of urushiol specific suppressor T-cells. J. Invest. Dermatol. 92:46-52.

31. Kalish, R. S., and K. L. Johnson. 1990. Enrichment and function of urushiol (poison ivy) specific T-lymphocytes in lesions of allergic contact dermatitis to urushiol. J. Immunol. 145:3706-3713.

32. Gocinski, B. L., and R. E. Tigelaar. 1990. Roles of CD4+ and CD8+ T cells in murine contact sensitivity revealed by in vivo monoclonal antibody depletion. J. Immunol. 144:4121-4128.

33. Kalish, R. S., C. Morimoto, and S. F. Schlossman. 1988. Characterization of the T4 helper inducer subset for the generation of cytotoxicity to alloantigen. Cell. Immunol. 111:379-389.

34. Bhardwaj, K., and M. J. Colston. 1988. The processing and presentation of mycobacterial antigens by human monocytes. Eur. J. Immunol. 18:691-696.

35. Gimm, C. D., G. J. Freeman, J. G. Gribben, K. Sugita, A. S. Freeman, C. Morimoto, and L. M. Nadler. 1991. B-cell surface antigen B7 provides a costimulatory signal that induced T cells to proliferate and secrete interleukin 2. Proc. Natl. Acad. Sci. USA. 88:6575-6579.

36. Shimonkevitz, R., J. Kappler, P. Marrack, and H. Grey. 1983. Antigen recognition by $\mathrm{H}-2$-restricted T cells. I. Cell-free antigen processing. J. Exp. Med. 158:303-316.

37. Kurt-Jones, E. A., D. I. Beller, S. B. Mizel, and E. R. Unanue. 1985. 
Identification of a membrane-associated interleukin 1 in macrophages. Proc. Natl. Acad. Sci. USA. 82:1204-1208.

38. Jenkins, M. K., P. S. Taylor, S. D. Norton, and K. B. Urdahl. 1991. CD28 delivers a costimulatory signal involved in antigen-specific IL2 production by human T cells. J. Immunol. 147:2461-2466.

39. Kalish, R. S., J. A. Wood, and A. LaPorte. 1993. CD28 co-stimulation is a second signal in the response of human CD8 T-cells to urushiol. Clin. Res. 41:455a. (Abstr.)

40. Byers, V. S., W. L. Epstein, N. Castagnoli, and H. Baer. 1979. In vitro studies of poison oak immunity. I. In vitro reaction of human lymphocytes to urushiol. J. Clin. Invest. 64:1437-1448.

41. Tapper, H., and R. Sundler. 1990. Role of lysosomal and cytosolic $\mathrm{pH}$ in the regulation of macrophage lysosomal enzyme secretion. Biochem. J. 272:407414.

42. Lukacs, G. L., O. D. Rotstein, and S. Grinstein. 1990. Phagosomal acidification is mediated by a vacuolar-type $\mathrm{H}^{+}$-ATPase in murine macrophages. $J$. Biol. Chem. 265:21099-21107.

43. Ohkuma, S., and B. Poole. 1978. Fluorescence probe measurement of the intralysosomal $\mathrm{pH}$ in living cells and the perturbation of $\mathrm{pH}$ by various agents. Proc. Natl. Acad. Sci. USA. 75:3327-3331.

44. Adorini, L., S. J. Ullrich, E. Appella, and S. Fuchs. 1990. Inhibition by brefeldin A of presentation of exogenous protein antigens to MHC class II-restricted T cells. Nature (Lond.). 346:63-66.

45. Sinigaglia, F., D. Scheidegger, G. Garotta, R. Scheper, M. Pletscher, and A. Lanzavecchia. 1985. Isolation and characterization of $\mathrm{Ni}$-specific $\mathrm{T}$-cell clones from patients with Ni-contact dermatitis. J. Immunol. 135:3929-3932.
46. Löfström, A., and H. Wigzell. 1986. Antigen specific human T-cell lines specific for cobalt chloride. Acta. Derm. Venereol. (Stockh.). 60:200-206.

47. Ortmann, B., S. Martin, A. von Bonin, E. Schiltz, H. Hoschutzky, and H. U. Weltzien. 1992. Synthetic peptides anchor T-cell specific TNP epitopes to MHC antigens. J. Immunol. 148:1445-1450.

48. Martin, S., B. Ortmann, U. Pflugfelder, U. Birsner, and H. U. Weltzien. 1992. Role for hapten-anchoring peptides in defining hapten-epitopes for MHCrestricted cytotoxic T cells. J. Immunol. 149:2569-2575.

49. Weltzien, H. U., S. Hebbelmann, U. Pflugfelder, H. Ruh, B. Ortmann, S. Martin, and A. Iglesias. 1992. Antigen contact sites in class I major histocompatibility complex-restricted trinitrophenyl-specific $\mathrm{T}$ cell receptors. Eur. J. Immunol. 22:863-866.

50. Romagnoli, P., and F. Sinigaglia. 1991. Selective interaction of $\mathrm{Ni}$ with an MHC-bound peptide. EMBO. (Eur. Mol. Biol. Organ.) J. 10:1303-1306.

51. Shear, N. H., S. P. Spielberg, D. M. Grant, B. K. Tang, and W. Kalow. 1986. Differences in metabolism of sulfonamides predisposing to idiosyncratic toxicity. Ann. Intern. Med. 105:179-184.

52. Claesen, M., M. A. A. Moustafa, J. Adline, D. Vandervorst, and J. H. Poupaert. 1982. Evidence for an arene oxide-NIH shift pathway in the metabolic conversion of phenytoin to 5-(4-hydroxyphenyl)-5-phenylhydantoin in the rat and man. Drug Metab. Dispos. 10:667-671.

53. Boecker, C., M. Hertl, and H. F. Merk. 1993. Dermal T lymphocytes from sulfamethoxazole-induced bullous exanthem are stimulated by allergen-modified microsomes. J. Invest. Dermatol. 100:540a. (Abstr.)

54. Hertl, M., H. Bohlen, F. Jugert, C. Boecker, R. Knaup, and H. F. Merk. 1993. Predominance of epidermal CD8 + T lymphocytes in bullous cutaneous reactions caused by beta-lactam antibiotics. J. Invest. Dermatol. 101:794-799. 